\title{
Non-steroidal anti-inflammatory drug ingestion: retrospective study of 272 bleeding or perforated peptic ulcers.
}

\author{
F.H. Smedley, M. Taube, R. Leach and C. Wastell \\ Academic Surgical Unit, Westminster Hospital, Dean Ryle Street, London SWIP 2AP, UK.
}

\begin{abstract}
Summary: The ingestion of non-steroidal anti-inflammatory drugs (NSAID) in 272 patients with bleeding or perforated peptic ulcer was compared with 272 age/sex matched controls. A significantly higher proportion of patients with gastric ulcers had received NSAID than those with duodenal ulcers. Twelve of $90(13 \%)$ patients admitted with bleeding duodenal ulcers had received NSAID compared with 11 of $26(42 \%)$ patients with bleeding gastric ulcers $(P=0.003)$. Sixteen of $132(12 \%)$ patients with perforated duodenal ulcer were taking NSAID compared with 8 of $24(33 \%)$ patients with perforated gastric ulcer. Thirty eight percent of patients with both bleeding and perforated gastric ulcers had received NSAID compared with $13 \%$ bleeding and perforated duodenal ulcers $(P<0.002)$.

This study confirms the association of NSAID and complicated peptic ulcer in patients of over 65 years and highlights the particular susceptibility of the gastric mucosa to their injurious effect.
\end{abstract}

\section{Introduction}

Non-steroidal anti-inflammatory drugs (NSAID) are very effective in the treatment of arthritis but their use is associated with significant morbidity and mortality from the complications of peptic ulceration. ${ }^{1-7}$ The prevalence of peptic ulceration in patients receiving NSAID lies between $17 \%$ and $31 \%{ }^{8-10}$

It has been suggested that elderly patients receiving NSAID are the most likely to develop the complications of peptic ulceration. ${ }^{4,7,12}$ The incidence of perforated peptic ulcer is increasing in the elderly ${ }^{12}$ with the number decreasing in men and increasing in women. ${ }^{12}$ The use of NSAID has been suggested as the prime reason for this ${ }^{4-6,11,12}$ but other factors such as cigarette smoking ${ }^{13}$ may also be important. It is reported that NSAID can also modify the symptoms of the ulcer, which may result in diagnostic delay and a poorer prognosis. ${ }^{14}$ The association of NSAID with the complications of duodenal ulceration has been harder to prove than that with gastric ulceration.

This study was performed to investigate the relationship between NSAID ingestion in patients above and below 65 years admitted with bleeding or perforated peptic ulcers. We also wanted to compare the prevalence of NSAID ingestion in patients with complicated gastric and duodenal ulcers.

Correspondence: F.H. Smedley, M.S., F.R.C.S.

Accepted: 9 June 1989

\section{Methods}

The medical records of 272 consecutive patients admitted as emergencies to St. Stephen's Hospital, Chelsea, with bleeding or perforated peptic ulcers between the years of 1977 and 1982 were reviewed to examine the prevalence of NSAID ingestion. These were compared with 272 controls matched for age, sex and year of admission, selected from the same hospital population.

Control patients were chosen by picking notes out of the filing cabinets at random until exact year of admission, age and sex match with peptic ulcer patients was found. The age and sex of the controls was established from the cover of the notes before they were examined for a history of NSAID ingestion. Controls had any diagnosis other than peptic ulceration. The diagnosis of ulcer type was made at laparotomy, endoscopy or barium meal. The data on NSAID intake was obtained by examining the medical records with details obtained from the houseman's clerking, general practitioner letters and summaries. Only patients who were receiving non-aspirin NSAID on admission were included in the NSAID group and not those with a past medical history of NSAID ingestion.

Comparison between the study and control groups was by $\chi^{2}$ test ( \pm Yates correction), Fisher exact test and $95 \%$ confidence intervals. The relative risks in all the different groups were also calculated.

(C) The Fellowship of Postgraduate Medicine, 1989 
Results

\section{Patients}

The median age of the entire group was 52.9 years with a range of between 18 and 91 years (121 women, 151 men). Two hundred and twenty two patients had duodenal ulcer complications and 50 gastric ulcer complications. The median age of the perforated duodenal ulcer (PDU) group was 52 years with a range between 18 years and 90 years ( 76 men, 56 women). The median age of the bleeding duodenal ulcer (BDU) group was 48.6 years with a range between 20 and 89 years (49 men, 41 women). The median age of the perforated gastric ulcer (PGU) group was 57.8 years with a range between 27 and 91 years $(13$ men, 11 women). In the bleeding gastric ulcer (BGU) group the median age was 68.3 years with a range between 26 and 89 years (13 men, 13 women).

\section{NSAID ingestion}

The prevalence of NSAID ingestion in bleeding and perforated peptic ulcer disease is shown in Table $I$.

More patients with bleeding $(P=0.003)$ and perforated $(P=0.005)$ peptic ulcers had received NSAID than controls. Twenty eight of $222(13 \%)$ patients with bleeding or perforated duodenal ulcers had received NSAID compared with 19 of $50(38 \%)$ patients with bleeding and perforated gastric ulcers $\left(P<0.002, \chi^{2}\right)$. Twelve of 90 patients with BDU received NSAID compared with 11 of 26 BGU $\left(P=0.003, \chi^{2}\right)$. Sixteen of 132 patients with PDU had received NSAID compared with 8 of 24 PGU $\left(P=0.019, \chi^{2}\right)$.

The increased relative risk of NSAID ingestion in all the gastric ulcer patients compared with all those with duodenal ulcer was 3.85:1 (95\% confidence limits 2.17-6.83 - Homogeneity $\chi^{2} 2.54$ ). This strongly suggests that the relative risk is higher in gastric than duodenal ulcers but this difference did not reach the $5 \%$ level.

Age $(<65>$ )

The data was divided into patients under and over 65 years (Table II). Below the age of 65 there was no significant difference in NSAID ingestion between patients with peptic ulcers and controls. In patients above 65 , however, there were significant differences for bleeding duodenal ulcer $(P=0.004)$, perforated gastric ulcer $(P=0.004)$, perforated duodenal ulcer $(P=0.03)$ and bleeding gastric ulcer $(P=0.012)$.

Fourteen of $27(51.8 \%)$ of the combined bleeding and perforated gastric ulcer group, over 65 , had received NSAID compared with 16 of $53(30 \%)$ of the equivalent duodenal ulcer patients $\left(P=0.058, \chi^{2}\right.$ test $)$.

Table III shows the relative risks of NSAID ingestion in patients with ulcers compared with controls. The relative risks were higher in the $>65$ year old age group than in the $<65$ year old group in both bleeding and perforated ulcers. Two patients were receiving aspirin and NSAID and one patient was receiving NSAID and steroids.

\section{Discussion}

In this study NSAID ingestion was more prevalent in patients with the complications of gastric, rather than duodenal ulcers. This may explain why it has been more difficult to prove the association of NSAID with the complications of duodenal ulceration in the past.

Table I Prevalence of NSAID ingestion in patients with peptic ulcers and matched controls $(95 \%$ confidence limits in parenthesis).

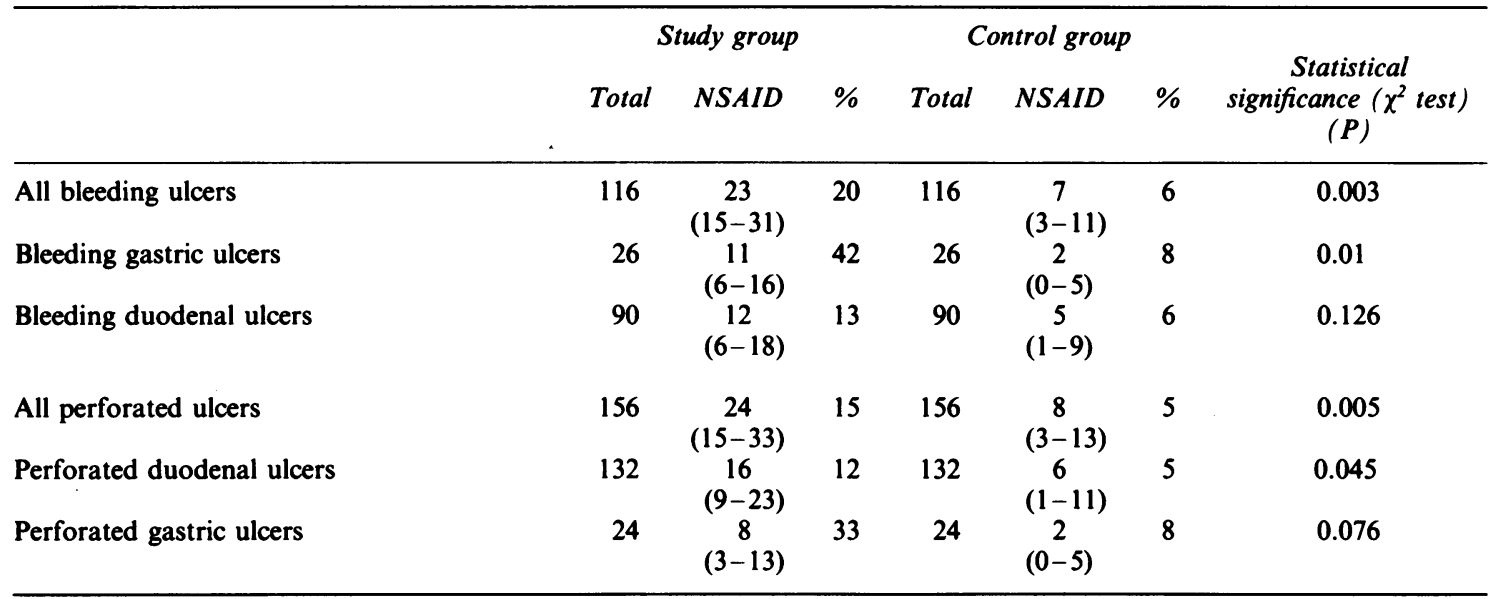


Table II Ingestion of NSAIDs in patients with bleeding or perforated duodenal (DU) and gastric (GU) ulcers compared with controls for specified age groups

\begin{tabular}{|c|c|c|c|}
\hline & Taking NSAID & No NSAID & Total \\
\hline \multicolumn{4}{|l|}{ Under 65} \\
\hline Perforated DU & $6(6 \%)$ & 91 & 97 \\
\hline Controls & $4(4 \%)$ & 93 & 97 \\
\hline \multicolumn{4}{|l|}{$\left(P=0.745 \chi^{2}\right.$ test $)$} \\
\hline Bleeding DU & $6(8 \%)$ & 67 & 72 \\
\hline \multicolumn{4}{|l|}{$\left(P=0.743 \chi^{2}\right.$ test $)$} \\
\hline Perforated GU & $3(18.8 \%)$ & 13 & 16 \\
\hline \multicolumn{3}{|l|}{$(P=0.35$ Fisher exact test $)$} & 16 \\
\hline Bleeding GU & $2(14.0 \%)$ & 5 & 7 \\
\hline $\begin{array}{l}\text { Controls } \\
\text { (no statistics valid) }\end{array}$ & $0(0 \%)$ & 7 & 7 \\
\hline \multicolumn{4}{|l|}{ Over 65} \\
\hline Perforated DU & $10(28.5 \%)$ & 25 & 35 \\
\hline $\begin{array}{l}\text { Controls } \\
\left(P=0.026 \chi^{2} \text { test }+ \text { Yates correction }\right)\end{array}$ & $2(6 \%)$ & 33 & 35 \\
\hline Bleeding DU & $6(33.3 \%)$ & 12 & 18 \\
\hline $\begin{array}{l}\text { Controls } \\
(P=0.0038 \text { Fisher exact test })\end{array}$ & $1(5.5 \%)$ & 17 & 18 \\
\hline Perforated GU & $5(62.5 \%)$ & 3 & 8 \\
\hline $\begin{array}{l}\text { Controls } \\
(P=0.0035 \text { Fisher exact test })\end{array}$ & $1(12.5 \%)$ & 7 & 8 \\
\hline Bleeding GU & $9(47.4 \%)$ & 10 & 19 \\
\hline $\begin{array}{l}\text { Controls } \\
\left(P=0.012 \chi^{2} \text { test }\right)\end{array}$ & $2(10.5 \%)$ & 17 & 19 \\
\hline
\end{tabular}

Table III Table of the relative risks of NSAID ingestion

\begin{tabular}{|c|c|c|}
\hline Ulcer type & $\underset{(<65 />65)}{\text { Age }}$ & Relative risk \\
\hline BDU & $<65$ & $\begin{array}{c}1.55 \\
(0.4-5.6)\end{array}$ \\
\hline BDU & $>65$ & $\begin{array}{c}8.50 \\
(1.2-62.3)\end{array}$ \\
\hline PDU & $<65$ & $\begin{array}{c}1.53 \\
(0.4-5.6)\end{array}$ \\
\hline PDU & $>65$ & $\begin{array}{c}6.60 \\
(1.5-28.4)\end{array}$ \\
\hline BGU & $<65$ & - \\
\hline BGU & $>65$ & $\begin{array}{c}10.31 \\
(2.3-58.7)\end{array}$ \\
\hline PGU & $<65$ & $\begin{array}{c}3.46 \\
(0.4-33.7)\end{array}$ \\
\hline PGU & $>65$ & $\begin{array}{c}11.67 \\
(1.1-120)\end{array}$ \\
\hline
\end{tabular}

BDU $=$ bleeding duodenal ulcer; $\quad$ PDU $=$ perforated duodenal ulcer; $\mathbf{B G U}=$ bleeding gastric ulcer; $\mathbf{P G U}=$ perforated gastric ulcer.
The mean age in the gastric ulcers in this study was slightly higher than in the duodenal ulcers which may have contributed to the higher percentages of NSAID ingestion found in these patients.

This view is confirmed by Glarborg Jorgenson ${ }^{2}$ who found that $31 \%$ of patients with PGU had received NSAID compared with only $13 \%$ of PDU. Collier and Pain $^{4}$ report $44 \%$ for PGU and $32 \%$ for PDU. Sommerville et al. ${ }^{7}$ did not find that the increased relative risk of taking NSAID in BGU compared with BDU was significant, but the relative risk was 3.7 in BGU and 2.7 in BDU compared with hospital based controls. In women the relative risk of taking NSAID compared with hospital based controls was 4.3 in BGU and 1.6 in BDU. Mortality from bleeding and perforated gastric ulcer was twice that of these complications in duodenal ulceration. ${ }^{6}$

The data in this study was from retrospective note review and there are biases inherent in using such a method. We probably underestimated the number of controls and study patients taking NSAID. There is also bias from the observer and from the recorded 
history with most doctors making a more thorough drug enquiry in patients with a bleeding or perforated peptic ulcer. Retrospective note review is inaccurate in assessing the intake of non-prescribed drugs. These factors would not, however, explain the differences found in the $>65$ year old group or the stronger association with gastric ulcer.

\section{References}

1. Thompson, M.R. Indomethacin and perforated peptic ulcer. Br Med J 1980, 280: 448.

2. Glarborg Jorgenson, T. Drug consumption before perforation of peptic ulcer. Br J Surg 1977, 64: 247-249.

3. Duggan, J.M. Aspirin injection and perforated peptic ulcer. Gut 1972, 13: 631-633.

4. Collier, St. J. \& Pain, J.A. Non-steroidal antiinflammatory drugs and peptic ulcer perforation. Gut 1985, 26: 359-363.

5. O'Brien, J.D. \& Burnham, W.R. Bleeding from peptic ulcers and use of non-steroidal anti-inflammatory drugs in the Romford area. $\mathrm{Br}$ Med J 1985, 291: 1609-1610.

6. Armstrong, C.P. \& Blower, A.L. Non-steroidal antiinflammatory drugs and life threatening complications of peptic ulceration. Gut 1987, 28: 527-532.

7. Sommerville, K., Faulkner, G. \& Langman, M. Nonsteroidal anti-inflammatory drugs and bleeding peptic ulcer. Lancet 1986, i: 462-464.

8. Sun, D.C., Roth, S.H., Mitchell, C.S. \& Englund, D.W. Upper gastrointestinal disease in rheumatoid arthritis. Am J Dig Dis 1974, 19: 405-410.
This study confirms the danger of NSAID ingestion to patients of over 65 years and highlights the particular susceptibility of the gastric mucosa to their injurious effect. Particular care must be taken with these drugs which may modify the symptoms of the ulcer they produce, especially now they are becoming more readily available to the general public.

9. Silvoso, G.R., Ivey, K.J. \& Butt, J.H. Incidence of gastric lesions in patients with rheumatic disease on chronic aspirin therapy. Ann Intern Med 1979, 91: 517-520.

10. Caruso, I. \& Bianchi, P.G. Gastroscopic evaluation of anti-inflammatory agents. $\mathrm{Br}$ Med $J$ 1980, 280: 75-78.

11. Watkins, R.M., Dennison, A.R. \& Collin, J. Whatever happened to perforated peptic ulcer. Br J Surg 1984, 71: 774-776.

12. Walt, R., Logan, R., Katschinski, B., Ashley, J. \& Langman, M. Rising frequency of ulcer perforation in elderly people in the United Kingdom. Lancet 1986, i: 489-492.

13. Smedley, F., Hickish, T., Taube, M., Yale, C., Leach, R. \& Wastell, C. Perforated duodenal ulcer and cigarette smoking. J R Soc Med 1988, 81: 92-94.

14. Skander, M.P. \& Ryan, F.P. Non-steroidal antiinflammatory drugs and pain free peptic ulceration in the elderly. $\mathrm{Br}$ Med J 1988, 297: 833-834. 